\title{
Sonication-assisted synthesis of polystyrene (PS)/organoclay nanocomposites: influence of clay content
}

\author{
Kelothu Suresh $^{1} \cdot$ R. Vinoth Kumar ${ }^{1}$ Manish Kumar' ${ }^{1}$ M. Jeyapriya ${ }^{2}$. \\ R. Anbarasan ${ }^{2}$ G. Pugazhenthi ${ }^{1}$
}

Received: 3 March 2017/ Accepted: 5 April 2017/Published online: 11 April 2017

(c) The Author(s) 2017. This article is an open access publication

\begin{abstract}
This article presents the synthesis of a series of polystyrene (PS)/organoclay nanocomposite films consisting of different contents of clay (1-7 wt \%) by sonicationcoupled solvent-blending technique. The prepared PS nanocomposite films were characterized using various techniques, including X-ray diffraction (XRD), Fourier transform infrared spectroscopy (FTIR), transmission electron microscopy (TEM), and thermal gravimetric analysis (TGA). The XRD and TEM results revealed the formation of exfoliated nanocomposites at lower loading of organoclay $(<5 \mathrm{wt} \%)$. The presence of various functional groups in the organoclay and PS/organoclay nanocomposite was verified by FTIR spectra. The thermal stability of PS nanocomposites was significantly improved as compared to pristine PS, which is evident from TGA analysis. When $10 \%$ mass loss was chosen as a point of reference, the thermal degradation temperature of PS nanocomposite holding $7 \mathrm{wt} \%$ of organoclay was found to be $30{ }^{\circ} \mathrm{C}$ more over pristine PS. The thermal kinetic parameters such as activation energy $\left(E_{\mathrm{a}}\right)$, pre-exponential factor $(A)$, and the order of reaction $(n)$ were determined by employing the Coats-Redfern model. Thermal degradation reaction mechanism of PS nanocomposites was also investigated.
\end{abstract}

G. Pugazhenthi

pugal@iitg.ernet.in

1 Department of Chemical Engineering, Indian Institute of Technology Guwahati, Guwahati, Assam 781039, India

2 Department of Polymer Technology, Kamaraj College of Engineering and Technology, Virudhunagar, Tamil Nadu 626001, India
Keywords Polystyrene - Organoclay · Nanocomposites · Thermal degradation · TEM

\section{Introduction}

Nanocomposite is one of the promising fields for current research and development in all the technical disciplines (Sureshkumar et al. 2016; Dhanalakshmi et al. 2013). Polymer/layered silicate nanocomposites (PLSN) display a significant interest among the industry and academia owing to their enhanced properties over conventional (micro and macro) composites. The nano-sized-modified clay fillers provide especially more interfacial area per volume between the polymer matrix and nanofillers, and therefore are responsible for the enhancement of mechanical, gas barrier, thermal stability, and fire retardant properties in conjunction with pristine polymers (Kumar et al. 2015; Mallakpour and Dinari 2014).

Depending on clay dispersion extent in the polymer matrix, two kinds of morphology can be observed, i.e., exfoliated and intercalated nanocomposites. For developing these polymer nanocomposites, there are three experimentally proven strategies: in situ polymerization, solvent blending, and melt compounding (Kumar et al. 2015). Among these techniques, solvent blending method is broadly used for the fabrication of polymer nanocomposites as it consistently offers exfoliated materials. In the solvent blending method, synthesizing conditions that control the homogeneity of the constituents are solvent, refluxing time, and temperature, which can lead to design the materials with desired properties.

Numerous researchers have reported the synthesis and characterization of polymer nanocomposites. Qiu et al. (2005) synthesized the PS/Zn-Al LDH nanocomposites

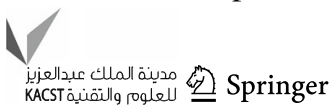


using solution intercalation technique and validated the exfoliated $\mathrm{Zn}-\mathrm{Al} \mathrm{LDH}$ in the PS polymer by TEM study. The thermal analysis also showed the improved decomposition temperature $\left(16^{\circ} \mathrm{C}\right)$ when compared to pristine PS. Botan et al. (2012) prepared PS/LDH nanocomposites with bulk polymerization method. They reported that the flame retardancy was improved by $50.6 \%$ for $\mathrm{PS} / \mathrm{Mg}-\mathrm{Al}$ LDH 5\% composition. Enhanced thermal and flammability properties for the PS/LDH composites have also been conveyed by other researchers (Majoni 2015; Tai et al. 2011). Adopting in situ thermal polymerization, Yeh et al. (2004) prepared a series of PS/clay composites and inferred improved anticorrosive and thermal characteristics of the nanocomposites. Poly(ethylene terephthalate)/clay composite was fabricated and its thermal oxidative degradation behaviors were precisely examined (Wu et al. 2002; Zhao et al. 2003).

The ultimate motivation of this study is to prepare solvent blending-based PS nanocomposites (1-7 wt\% of organoclay). The effect of clay content on the thermal and structural characterization parameters of PS/organoclay composites has been examined. Based on the TGA data, the kinetic study of PS nanocomposites is carried out by Coats-Redfern method. Furthermore, Criado method was followed to evaluate the pertinent reaction mechanisms during thermal decomposition of PS and PS nanocomposites.

\section{Experimental}

\section{Materials}

Polystyrene granules used as the matrix for polymer nanocomposites were purchased from the National Chemicals Ltd., Gujarat, India. Surface-modified clay with 15-35 wt $\%$ octadecylamine and 0.5-5 wt\% aminopropyltriethoxysilane was supplied by Sigma-Aldrich, USA. Xylene solvent was obtained from Merck (I) Ltd, Mumbai.

\section{Synthesis of PS/organoclay nanocomposites}

The formation of PS/organoclay nanocomposites was done by a simple solvent blending technique combined with sonication process. The required quantity of organoclay (1, 3, 5, and $7 \mathrm{wt} \%$ with respect to PS) was suspended in xylene and stirred at room temperature for $2 \mathrm{~h}$. In order to achieve complete dispersion, the organoclay solution was further sonicated for $2 \mathrm{~h}$ using tip sonicator with $400 \mathrm{~kW}$. Polymer solution was prepared separately by dissolving desired amount of PS in xylene and stirred continuously for $2 \mathrm{~h}$ at ambient condition. After which, under continuous stirring condition, the PS solution was gradually added to organoclay solution that was eventually subjected to sonication for $2 \mathrm{~h}$. The blended PS/organoclay material was casted over the petri dish and made to stand for $12 \mathrm{~h}$ at ambient temperature. The solvent was evaporated from the PS nanocomposites films by vacuum drying for $6 \mathrm{~h}$ at $70{ }^{\circ} \mathrm{C}$. The pristine PS film was prepared by dissolving PS granules in xylene with continuous stirring for $12 \mathrm{~h}$ in the absence of organoclay. Note that, all the compositions are represented as organoclay, PS, PS 1, PS 3, PS 5, and PS 7 for modified clay, polystyrene, PS/organoclay 1 (wt $\%$ ), PS/ organoclay 3 (wt\%), PS/organoclay 5 (wt $\%$ ), and PS/ organoclay 7 (wt $\%)$, respectively. The composition of PS nanocomposites is presented in Table 1.

\section{Measurements}

XRD was carried out using a diffractometer (Make: Bruker, Model: D8 ADVANCE) in the $2 \theta$ range of $2^{\circ}-50^{\circ}$, with the scanning speed of $0.02 \%$ with Ni-filtered $\mathrm{Cu} \mathrm{K} \alpha$ radiation at room temperature. TEM analysis (Make: JEOL, Model: JEM 2100) was done at $200 \mathrm{kV}$ accelerating voltage. Fourier transform infrared (FTIR) analysis (Make: Shimadzu, Model: IRAffinity-1) was performed in the wave number between 4000 and $400 \mathrm{~cm}^{-1}$ for the synthesized samples in order to identify functional groups in the clay and clay-based PS nanocomposites. The thermogravimetric (TG) instrument (Make: Mettler Toledo, Model: TGA 851e/LF/1100) was employed to analyze the thermal behavior of the samples in the temperature range of $30-700{ }^{\circ} \mathrm{C}$ at $10{ }^{\circ} \mathrm{C} / \mathrm{min}$ heating rate and inert $\left(\mathrm{N}_{2}\right)$ environment with a flow rate of $60 \mathrm{~mL} / \mathrm{min}$.

\section{Results and discussion}

\section{XRD analysis}

The XRD spectra of various samples (organoclay, PS, and PS/organoclay nanocomposites) have been presented in Fig. 1. The important diffraction peak of organoclay appears at $2 \theta$ value of $4.15^{\circ}$. The $d$-spacing value of organoclay is found to be $2.13 \mathrm{~nm}$, which is estimated using Bragg's law $(d=\lambda / 2 \sin \theta$, with $\lambda=1.5406 \AA)$.

Table 1 Preparation chart for PS/organoclay nanocomposites

\begin{tabular}{lllll}
\hline Sample & $\begin{array}{l}\text { Organoclay loading } \\
(\mathrm{wt} \%)\end{array}$ & $\begin{array}{l}\text { Organoclay } \\
(\mathrm{g})\end{array}$ & $\begin{array}{l}\text { PS } \\
(\mathrm{g})\end{array}$ & $\begin{array}{l}\text { Solvent } \\
(\mathrm{mL})\end{array}$ \\
\hline PS & 0 & 0 & 5 & 109 \\
PS1 & 1 & 0.05 & 4.95 & 109 \\
PS 3 & 3 & 0.15 & 4.85 & 109 \\
PS 5 & 5 & 0.25 & 4.75 & 109 \\
PS 7 & 7 & 0.35 & 4.65 & 109 \\
\hline
\end{tabular}


Figure $1 \mathrm{~b}-\mathrm{d}$ illustrates no diffraction peak corresponding to (001) plan of clay in the PS nanocomposites (1-5 wt\% clay). This signifies a complete exfoliation situation. When the amount of organoclay increases to $7 \mathrm{wt} \%$, there is appearance of (001) peak of organoclay at $2 \theta=2.62^{\circ}$, corresponding to $3.38 \mathrm{~nm} \quad d$-spacing. For PS 7

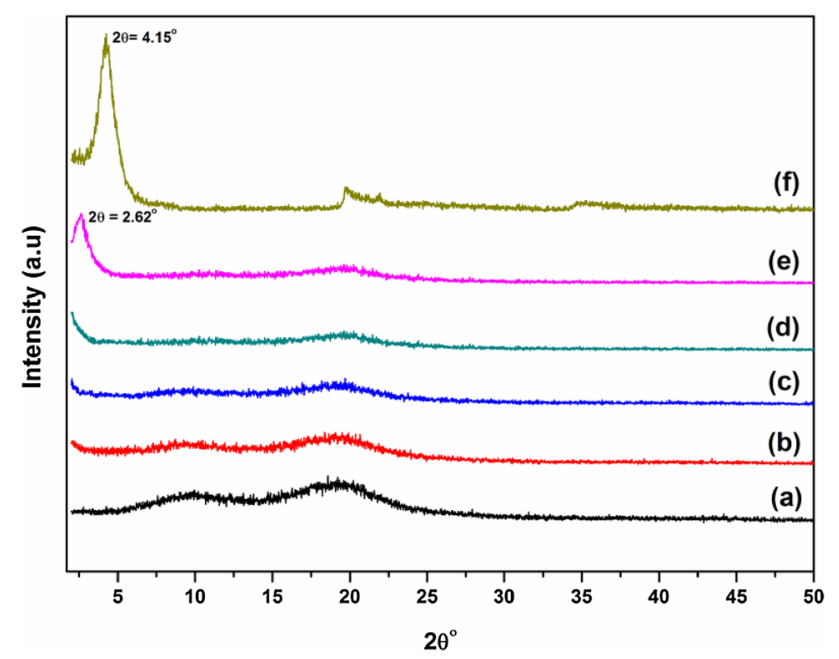

Fig. 1 XRD patterns of a PS, b PS 1, c PS 3, d PS 5, e PS 7, and f organoclay nanocomposite, $d$-spacing enhanced from 2.13 to $3.38 \mathrm{~nm}$, thereby indicating intercalated organoclay layers in the structure. In the investigation carried out by Yeh et al. (2004), exfoliated structure for $1 \mathrm{wt} \%$ loading for PS/clay nanocomposites was reported. However, the intercalated structures were obtained at higher loading (10 wt $\%)$.

\section{TEM analysis}

For further confirmation of nanocomposites structure, an extensive characterization of nanocomposites morphological investigation needs microscopic images. The TEM micrographs of PS/organoclay nanocomposites have been shown in Fig. 2. The black lines represent the organoclay, while the light regime corresponds to polymer matrix. Figure $2 \mathrm{a}-\mathrm{b}$ presents the isolated layers of organoclay that are distributed in the polymer for PS 1 and PS 3 nanocomposite samples. The arrow symbol shows the exfoliated morphology of PS/organoclay nanocomposites. Uthirakumar et al. (2005a) also demonstrated the formation of the exfoliated structure of PS/clay ( 1 and $3 \mathrm{wt} \%$ ) nanocomposites which was prepared by in situ polymerization technique. Figure $2 \mathrm{c}$ represents the partially exfoliated structure for PS 5 nanocomposite. The arrow mark represents the exfoliated, and the circle mark demonstrates
Fig. 2 TEM images of a PS 1, b PS 3, c PS 5, and d PS 7
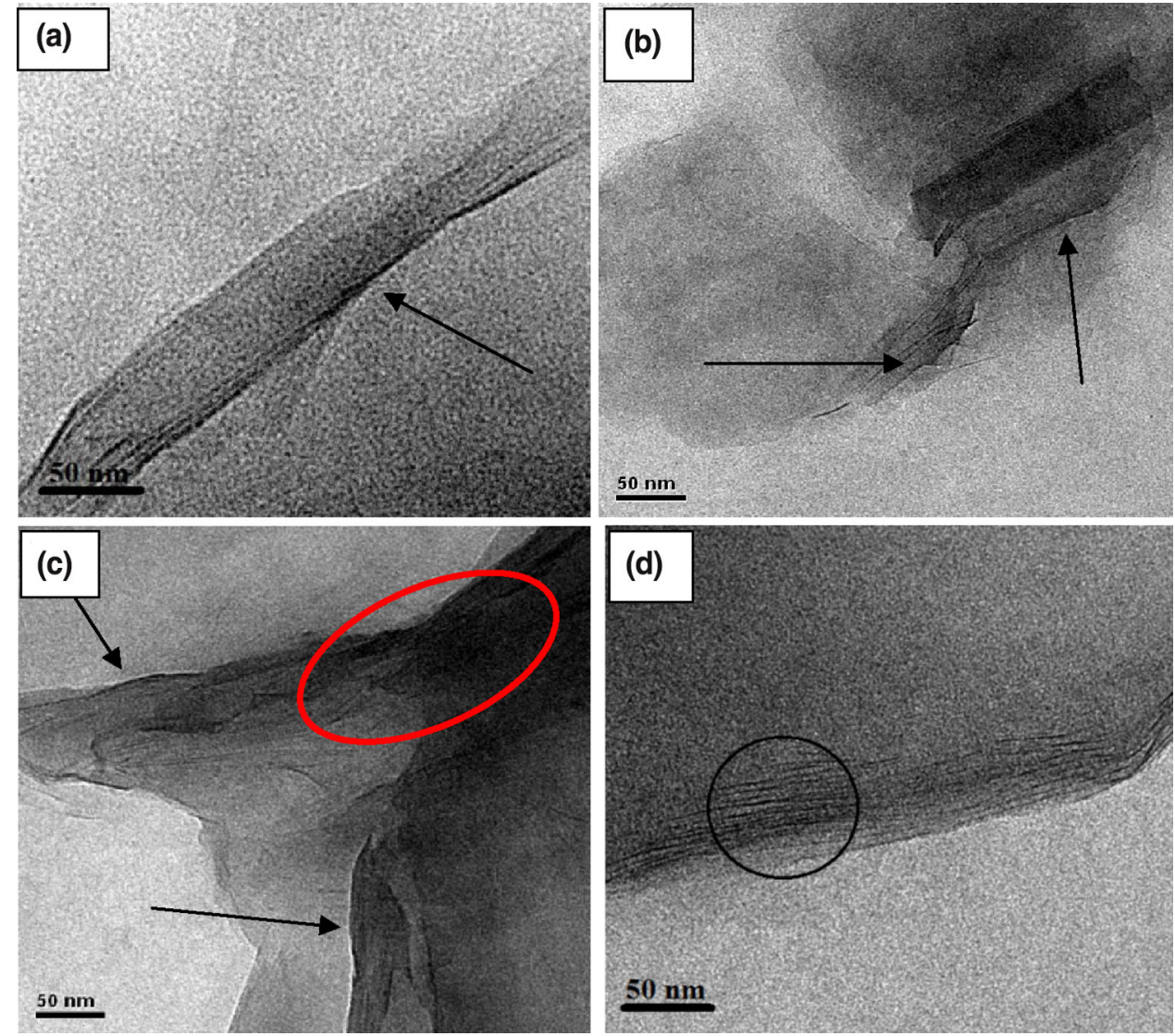

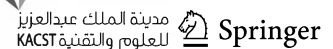


intercalated structure. In another work, Alansi et al. (2015) prepared the PS/LDH nanocomposites with 4 wt $\% \mathrm{Mg}-\mathrm{Al}$ LDH and obtained a mixed nanomorphology (i.e., exfoliated and intercalated). The obtained intercalated structure in PS 7 nanocomposite is in good agreement with the XRD graph (Fig. 1e).

\section{FTIR analysis}

FTIR analysis was performed to confirm the various functional groups present in the organoclay and pristine PS. Figure 3 depicts the FTIR spectra of pristine PS, organoclay, and PS nanocomposites. For pristine PS (Fig. 3a), the characteristic peaks observed at 3070 and $2930 \mathrm{~cm}^{-1}$ are assigned as aromatic and aliphatic $\mathrm{C}-\mathrm{H}$ stretching vibrations, respectively. The other peaks for $\mathrm{C}=\mathrm{C}$ stretching vibration, $\mathrm{CH}_{2}$ bending vibrations, and mono substituted benzene are obtained at $\left(1496 \mathrm{~cm}^{-1}\right),\left(1368 \mathrm{~cm}^{-1}\right)$ and $\left(698 \mathrm{~cm}^{-1}\right)$, respectively (Madejova 2003). For organoclay (Fig. 3c), a broader and sharp peak at wave number $3630 \mathrm{~cm}^{-1}$ is designated as the $\mathrm{O}-\mathrm{H}$ stretching modes of interlayer $\mathrm{H}_{2} \mathrm{O}$ molecules. The assignments for the sharp peaks at 2922, 2849, and $1465 \mathrm{~cm}^{-1}$ are $\mathrm{CH}_{2}$ asymmetric, symmetric stretching, and in-plane scissoring vibrations, respectively. The sharp peak at $1636 \mathrm{~cm}^{-1}$ represents the bending vibration form of adsorbed and weaker bonds of water molecules. The broad band at $1048 \mathrm{~cm}^{-1}$ indicates the $\mathrm{Si}-\mathrm{O}$ stretching. The two prominent peaks at wave numbers of 463 and $521 \mathrm{~cm}^{-1}$ are $\mathrm{Mg}-\mathrm{O}$ bending vibrations and $\mathrm{Al}-\mathrm{O}$ stretching, respectively. Compared to pristine PS (Fig. 3a) and organoclay (Fig. 3c), the PS 5 sample (Fig. 3b) shows few new peaks that are $\mathrm{O}-\mathrm{H}$ stretching modes of interlayer $\mathrm{H}_{2} \mathrm{O}$ molecules $\left(3630 \mathrm{~cm}^{-1}\right), \mathrm{Si}-\mathrm{O}$ stretching $\left(1048 \mathrm{~cm}^{-1}\right)$, and $\mathrm{Mg}-\mathrm{O}$ bending vibrations $\left(463 \mathrm{~cm}^{-1}\right)$. From these peaks, the presence of organoclay in the PS polymer is confirmed . Wang et al. (2004) prepared the PS nanocomposites using different contents of clay (1-5 wt\%) using free radical polymerization method and they also obtained similar kind of results.

\section{TG analysis}

The thermogravimetric analysis (TGA) can facilitate to assess the enhancement of thermal properties of the nanocomposites. Figure 4 presents the TGA profiles of organoclay, pristine PS, and PS nanocomposites. For organoclay (Fig. 4a), a slight mass loss noticed at the temperature below $300{ }^{\circ} \mathrm{C}$ is attributed to the removal of physisorbed water as well as interlayer water. The mass loss in the range of $300-450{ }^{\circ} \mathrm{C}$ is owing to the decomposition of the organic modifier present in the clay. Further degradation at higher temperature (above $450{ }^{\circ} \mathrm{C}$ ) occurred due to dehydroxylation of aluminosilicate. In the PS nanocomposite samples (Fig. 4c-f), the major mass loss that occurred between 350 and $450{ }^{\circ} \mathrm{C}$ is due to the
Fig. 3 FTIR curves of a PS, b PS 5, and c organoclay

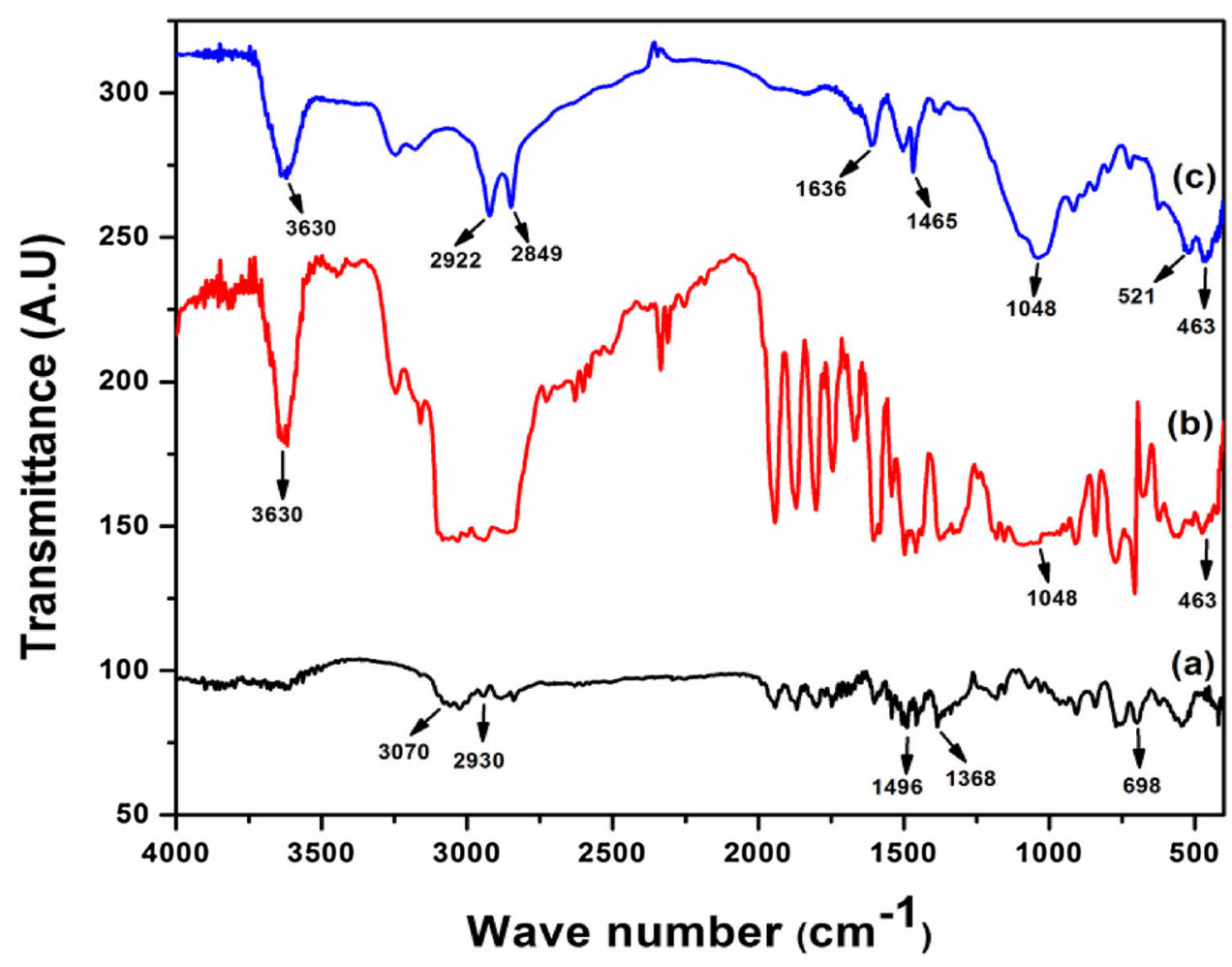


Fig. 4 TGA curves of a organoclay, b PS, c PS 1, d PS 3, e PS 5, and f PS 7

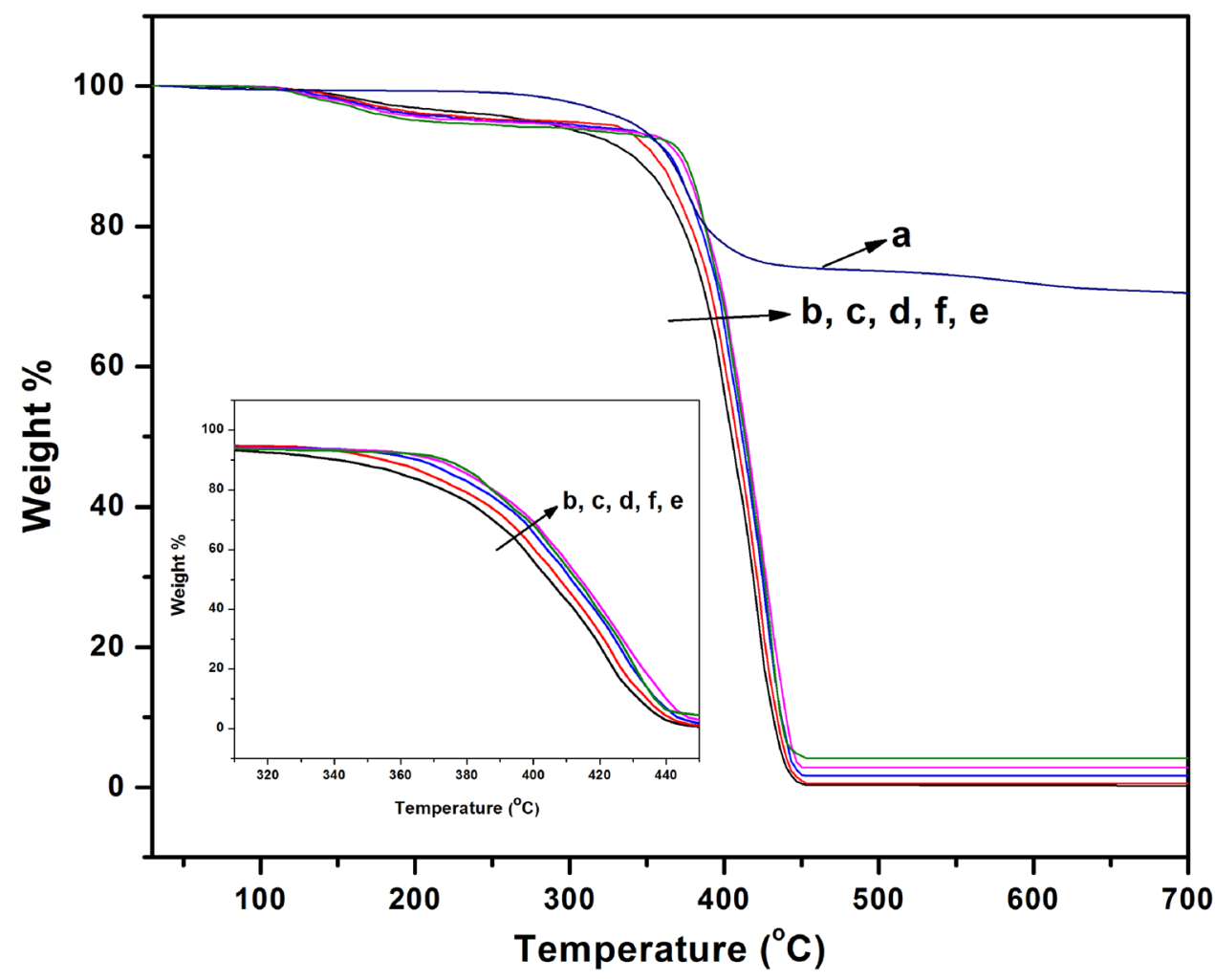

Table 2 Thermal degradation temperatures and kinetic parameters of different samples obtained from Coats-Redfern method

\begin{tabular}{lllllll}
\hline Sample & $\begin{array}{l}\text { Temperature at } \\
10 \mathrm{wt} \% \text { loss }{ }^{\circ} \mathrm{C}\left(T_{10 \%}\right)\end{array}$ & $\begin{array}{l}\Delta T_{10 \%} \\
\left({ }^{\circ} \mathrm{C}\right)\end{array}$ & $\begin{array}{l}\text { Reaction } \\
\text { order }(n)\end{array}$ & $\begin{array}{l}\text { Activation energy } \\
E_{\mathrm{a}}(\mathrm{kJ} / \mathrm{mol})\end{array}$ & $\begin{array}{l}\text { Pre-exponential } \\
\text { factor }(A)\end{array}$ & $\begin{array}{l}\text { Correlation } \\
\text { coefficient }(R)\end{array}$ \\
\hline PS & 340.8 & - & 0.2 & 89 & $8.88 \times 10^{5}$ & 0.993 \\
PS1 & 353.0 & 12.2 & 0.4 & 108 & $3.48 \times 10^{7}$ & 0.996 \\
PS 3 & 362.2 & 21.4 & 0.3 & 118 & $1.81 \times 10^{8}$ & 0.998 \\
PS 5 & 368.0 & 27.2 & 0.5 & 134 & $3.39 \times 10^{9}$ & 0.999 \\
PS 7 & 370.9 & 30.1 & 0.4 & 126 & $7.12 \times 10^{8}$ & 0.994 \\
\hline
\end{tabular}

degradation of organic modifier followed by structural decomposition of PS. Similar results have also been obtained by Zhang et al. (2007). Results of TGA analysis of PS nanocomposites demonstrate delayed decomposition relative to pristine PS. As the organoclay content increased, the decomposition temperature of the nanocomposites shifted to the elevated temperature. This clearly points out that PS/organoclay nanocomposites are more thermally stable than the pristine PS. With $10 \%$ mass loss as reference point, the thermal degradation temperatures for pristine PS and 1, 3, 5, and $7 \mathrm{wt} \%$ organoclay-based nanocomposites are $340.8,353,362.2,368$, and $370.9^{\circ} \mathrm{C}$, respectively. This elucidates that the thermal stability of PS nanocomposite is enhanced by $12-30{ }^{\circ} \mathrm{C}$ when compared to pristine PS (see Table 2). This improved thermal stability is attributed to the hindered effect of clay layers (platelets) for the diffusion of volatile decomposition products throughout the nanocomposite samples. In the nanocomposite, volatile products have to take a long and

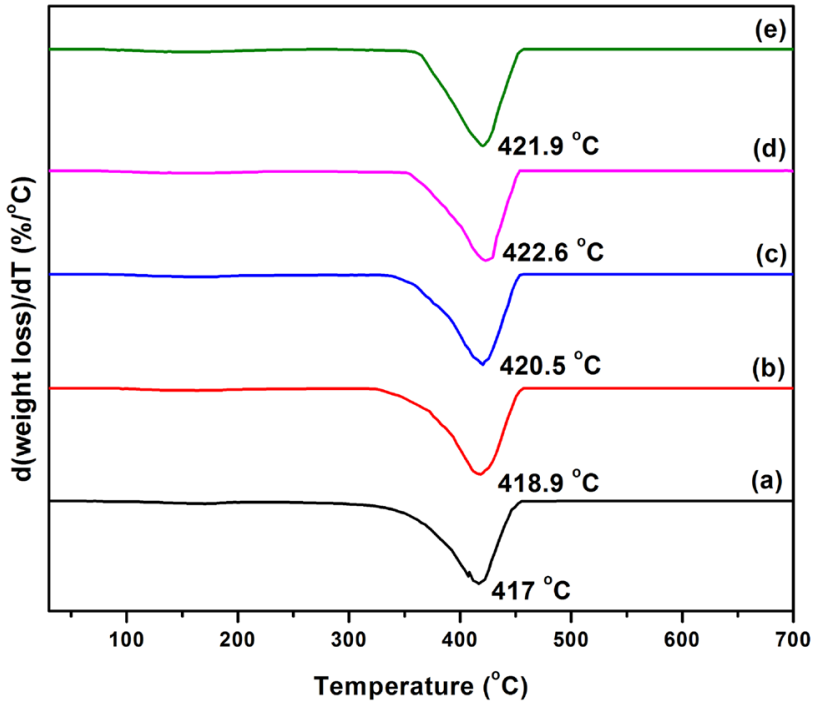

Fig. 5 TGA derivatives of a PS, b PS 1, c PS 3, d PS 5, and e PS 7 nanocomposites 

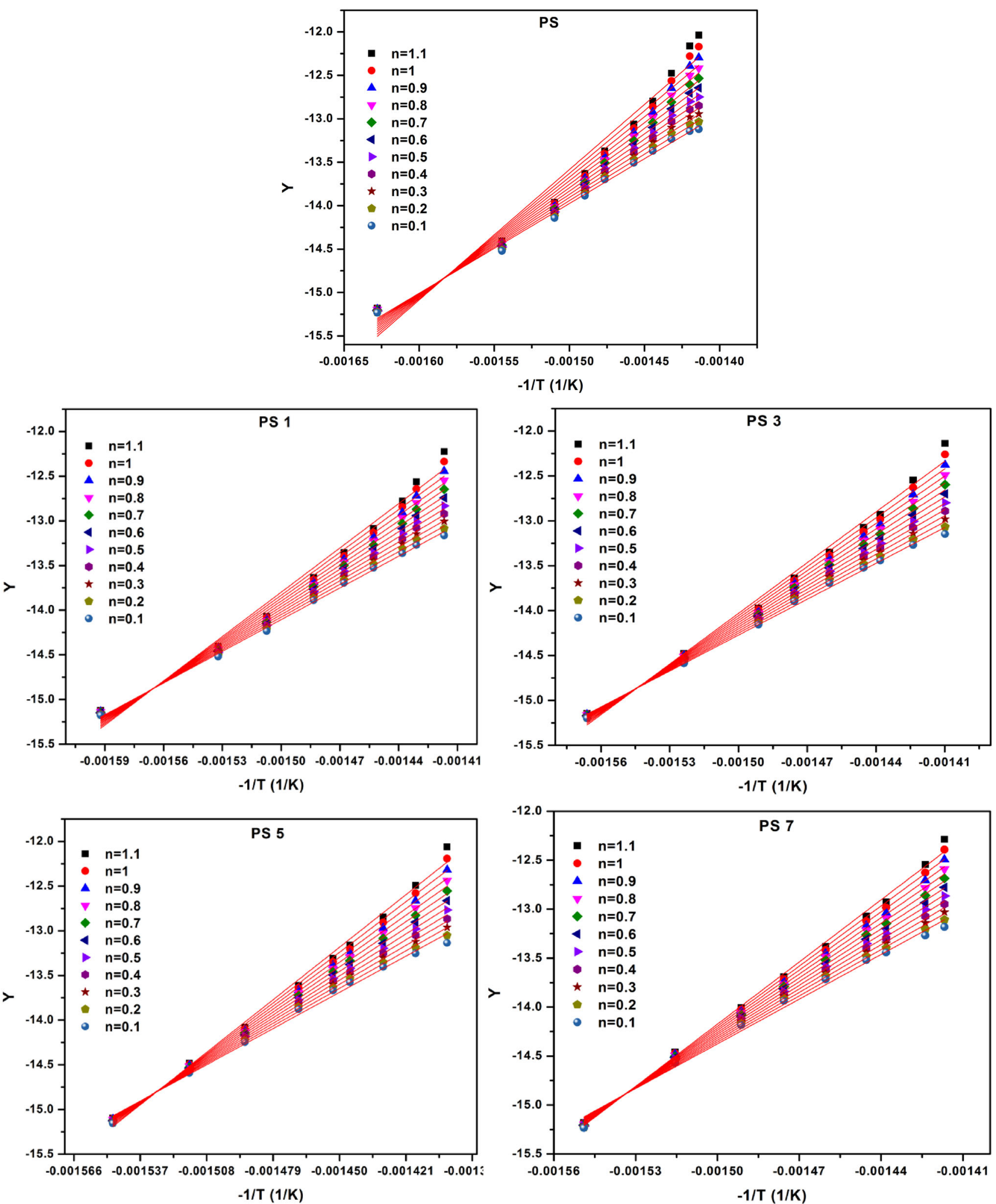

Fig. 6 Determination of kinetic parameters by plots of the left part in equation against $-1 / T$ using Coats-Redfern methods

tortuous path around impermeable clay platelets that are distributed in PS matrix as compared to pristine PS, where the diffusion of volatile products is much easier. Mohanty and Nayak (2007) also reported the enhanced thermal stability of $7{ }^{\circ} \mathrm{C}$ for PS nanocomposite containing $3 \mathrm{wt} \%$ of Na-MMT over pure PS. In another work reported by 
Uthirakumar et al. (2005b), high impact polystyrene (HIPS) nanocomposite synthesized with $5 \mathrm{wt} \%$ modified organoclay showed $18{ }^{\circ} \mathrm{C}$ enhancement in thermal stability as compared to pristine polymer. The first derivative of TGA plots shown in Fig. 5 clearly illustrates the pertinent enhancement in thermal stability for the said nanocomposites. In the figure, the peak refers to maximum degradation temperature $\left(T_{\max }\right)$ of the prepared samples. The $T_{\max }$ value for pristine PS is $417^{\circ} \mathrm{C}$, whereas the $T_{\max }$ value for the nanocomposites is found to be $422.6{ }^{\circ} \mathrm{C}$ for 5 $\mathrm{wt} \%$ organoclay loading. Similar findings were also reported by other researchers (Uthirakumar et al. 2005a).

\section{Coats-Redfern method for kinetics analysis}

Coats-Redfern method is well known for the determination of thermal degradation process parameters (reaction order, activation energy, and pre-exponential factor) using TG data (Coats and Redfern 1964).

Coats-Redfern adopts the following expressions:

$$
n=1 \quad \ln -\left(\frac{\ln (1-\alpha)}{T^{2}}\right)=\ln \left[\frac{A R}{\beta E_{\mathrm{a}}}\left(1-\frac{2 R T}{E_{\mathrm{a}}}\right)\right]-\frac{E_{\mathrm{a}}}{R T}
$$

$$
\begin{aligned}
& n \neq 1 \\
& \quad \ln -\left(\frac{1-(1-\alpha)^{1-n}}{(1-n) T^{2}}\right)=\ln \left[\frac{A R}{\beta E_{\mathrm{a}}}\left(1-\frac{2 R T}{E_{\mathrm{a}}}\right)\right]-\frac{E_{\mathrm{a}}}{R T}
\end{aligned}
$$

where, $\beta, T, E_{\mathrm{a}}, A, R$, and $\alpha$ are heating rate, temperature, activation energy, pre-exponential factor, gas constant, and fractional weight loss $\left(\alpha=\left(W_{0}-W_{t}\right) /\left(W_{0}-W_{\infty}\right)\right.$, where,
$W_{t}, W_{0}$, and $W_{\infty}$ are actual, initial, and final weight of the sample, respectively), respectively. These parameters have been determined using a plot of $-1 / T$ vs left-hand side expression in Eqs. (1) and (2) for different $n$ values and converging upon the relevant $\mathrm{n}$ value for which maximum correlation coefficient $(R)$ could be obtained. For such a plot, $E_{\mathrm{a}}$ and $A$ have been evaluated as slope and intercept of the best fit linear plot. The $E_{\mathrm{a}}$ for pristine PS, PS/organoclay nanocomposites consisting of $1,3,5$, and $7 \mathrm{wt} \%$ of organoclay is calculated to be $89,108,118,134$, and $126 \mathrm{~kJ} / \mathrm{mol}$, respectively. Figure 6 and Table 2 clearly demonstrate that the $E_{\mathrm{a}}$ of PS nanocomposites is increased by $19-45 \mathrm{~kJ} / \mathrm{mol}$ in comparison with pristine PS. Similar trends were reported by Chen and Wang (2007) for $E_{\mathrm{a}}$ of $\mathrm{PP}$ composites as compared to polymer.

\section{Criado method for reaction mechanism determination}

Criado et al. (1989) recommended the following expressions for reaction mechanism determination from thermal degradation process.

$Z(\alpha)=\frac{\beta}{A} g(\alpha) \frac{\mathrm{d} \alpha}{\mathrm{d} t} \mathrm{e}^{\frac{E_{a}}{R T}}$

$Z(\alpha)=\frac{\mathrm{d} \alpha}{\mathrm{d} t} \frac{E_{\mathrm{a}}}{R} \mathrm{e}^{\frac{E_{a}}{R T}} P(x)$,

where

$P(x)=\frac{\mathrm{e}^{-x}}{x} \frac{x^{3}+18 x^{2}+86 x+96}{x^{4}+20 x^{3}+120 x^{2}+240 x+120}$,

$g(\alpha)$ is an integral function expressed in terms of $\alpha$

Table 3 The expressions of $g(\alpha)$ for the commonly used reaction mechanism of solid state process

\begin{tabular}{lll}
\hline Mechanism & $g(\alpha)$ & Solid state process \\
\hline A2 & $-[\ln (1-\alpha)]^{1 / 2}$ & Nucleation and growth \\
A4 & $-[\ln (1-\alpha)]^{1 / 3}$ & Nucleation and growth \\
A3 & $-[\ln (1-\alpha)]^{1 / 4}$ & Nucleation and growth \\
R2 & {$\left[1-(1-\alpha)^{1 / 2}\right]$} & Phase boundary controlled reaction: contraction area \\
R3 & {$\left[1-(1-\alpha)^{1 / 3}\right]$} & Phase boundary controlled reaction: contraction volume \\
D1 & $\alpha^{2}$ & One-D diffusion \\
D2 & $(1-\alpha) \times \ln (1-\alpha)+\alpha$ & Two-D diffusion \\
D3 & {$\left[1-(1-\alpha)^{1 / 3}\right]^{2}$} & Three-D diffusion, Jander equation \\
D4 & $(1-2 / 3 \alpha)-(1-\alpha)^{2 / 3}$ & Three-D diffusion,Ginstling-Brounshtein equation \\
F1 & $-\ln (1-\alpha)$ & Random nucleation having one nucleus on individual particle \\
F2 & $1 /(1-\alpha)$ & Random nucleation having two nucleus on individual particle \\
F3 & $1 /(1-\alpha)^{2}$ & Random nucleation having two nucleus on individual particle \\
\hline & &
\end{tabular}



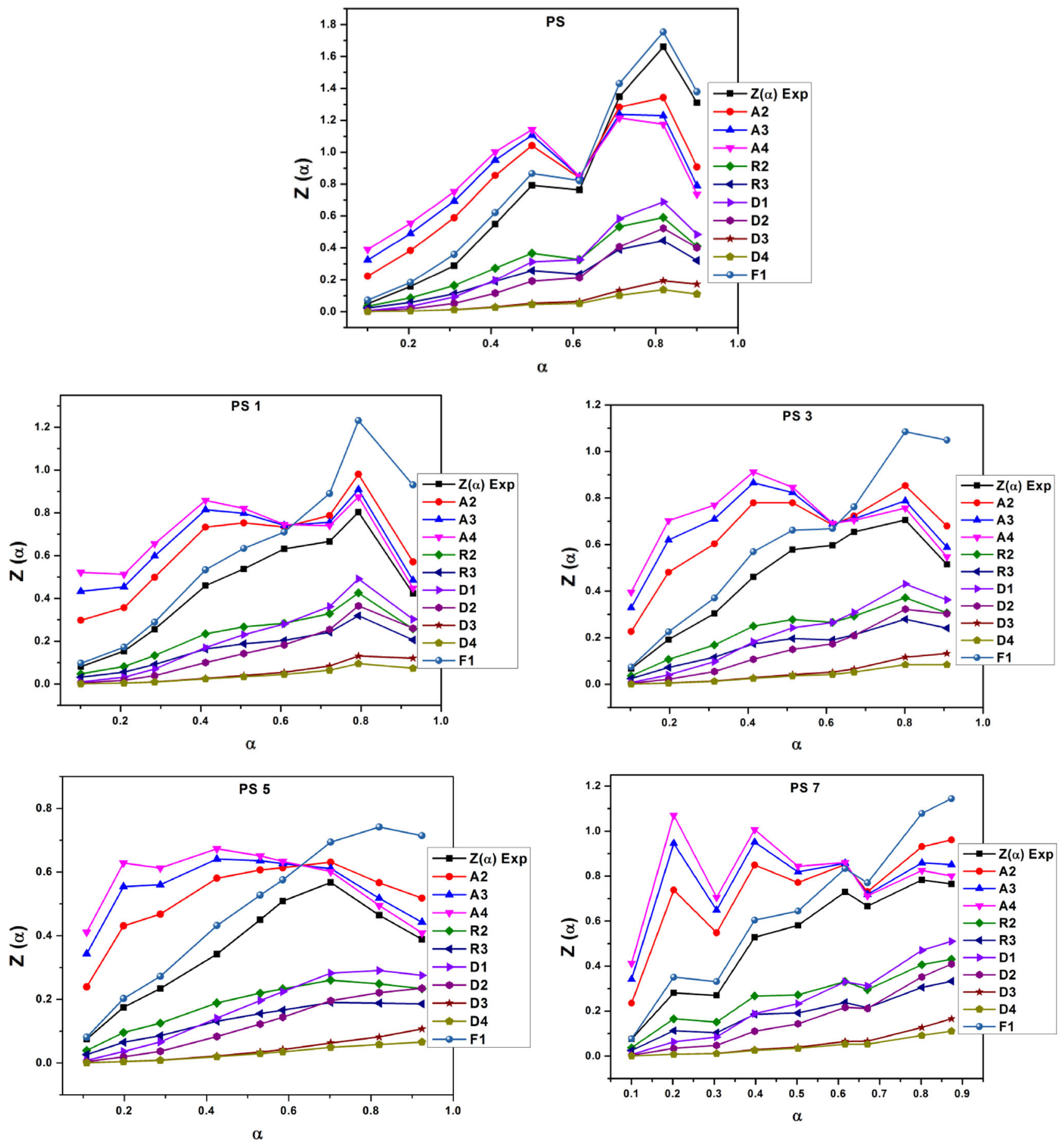

Fig. 7 Determination of the thermal degradation mechanism by plotting $Z(\alpha)$ versus $\alpha$ using Criado model

(conversion degree). For various solid reactions, $g(\alpha)$ has distinct expressions (see Table 3).

The obtained kinetic parameters are used to evaluate the various reaction mechanisms through Criado method. The master $Z(\alpha)$ versus $\alpha$ plot for the various reaction mechanisms and the experimental $Z(\alpha)$ versus $\alpha$ curve can be plotted using Eqs. (3) and (4), respectively. As shown in Fig. 7a, the experimental $Z(\alpha)$ versus $\alpha$ curve of pristine PS virtually matches with the master plot of $Z(F 1)$ and this affirms that pristine PS thermal decomposition follows F1 reaction mechanism involving one nucleusbased random nucleation on individual particle. In Fig. 7b-e, the experimental curve of PS nanocomposites follows $\mathrm{F} 1$ reaction mechanism at the initial conversion. 
Hence, it is apparent that the thermal decomposition system evolved slowly from F1 to A4 mechanism (nucleation and growth) with increasing decomposition temperature.

\section{Conclusions}

In the current article, organoclay was used as nanofiller for the synthesis of exfoliated PS nanocomposites via a facile solvent blending method. The XRD and TEM micrographs exhibited dissemination of organoclay layers in the PS. The TGA result demonstrated the effect of organoclay concentration on the thermal decomposition behavior of PS/ organoclay nanocomposites, which is improved relative to pristine PS. For $10 \%$ weight loss as a reference point, the thermal degradation temperature of PS nanocomposites increased by $12-30{ }^{\circ} \mathrm{C}$ with respect to the values evaluated for the pristine PS. Thermal degradation kinetics of PS/ organoclay nanocomposites have been investigated using Coats-Redfern method and among the studied samples, the PS nanocomposite with $5 \mathrm{wt} \%$ organoclay content has highest activation energy. The Criado model suggests that PS nanocomposites initially follow the F1 mechanism; however, with the higher temperature, the concerned system slowly transfers to A4 mechanism.

Open Access This article is distributed under the terms of the Creative Commons Attribution 4.0 International License (http:// creativecommons.org/licenses/by/4.0/), which permits unrestricted use, distribution, and reproduction in any medium, provided you give appropriate credit to the original author(s) and the source, provide a link to the Creative Commons license, and indicate if changes were made.

\section{References}

Alansi AM, Alkayali WZ, Al-qunaibit MH, Qahtan TF, Saleh TA (2015) Synthesis of exfoliated polystyrene/anionic clay MgAllayered double hydroxide: structural and thermal properties. RSC Adv 5:71441-71448

Botan R, Nogueira TR, Wypych F, Lona LMF (2012) In situ synthesis, morphology, and thermal properties of polystyrene$\mathrm{MgAl}$ layered double hydroxide nanocomposites. Polym Eng Sci 52:1754-1760

Chen Y, Wang Q (2007) Thermal oxidative degradation kinetics of flame-retarded polypropylene with intumescent flame-retardant master batches in situ prepared in twin-screw extruder. Polym Degrad Stabil 92:280-291

Coats AW, Redfern JP (1964) Kinetic parameters from thermogravimetric data. Nature 201:68-69

Criado JM, Malek J, Ortega A (1989) Applicability of the master plots in kinetic analysis of non-isothermal data. Thermochim Acta 147:377-385
Dhanalakshmi CP, Vijayalakshmi L, Narayanan V (2013) Synthesis and characterization of poly(4-vinyl pyridine-co-styrene)/FHAP nanocomposite and its biomedical application. Appl Nanosci $3: 373-382$

Kumar M, Chaudhary V, Suresh K, Pugazhenthi G (2015) Synthesis and characterization of exfoliated PMMA/Co-Al LDH nanocomposites via solvent blending technique. RSC Adv 5:39810-39820

Madejova J (2003) FTIR techniques in clay mineral studies. J Vib Spectrose 31:1-10

Majoni SJ (2015) Thermal and flammability study of polystyrene composites containing magnesium-aluminum layered double hydroxide $\left(\mathrm{MgAl}-\mathrm{C}_{16} \mathrm{LDH}\right)$, and an organophosphate. Therm Anal Calorim 120:1435-1443

Mallakpour S, Dinari M (2014) Structural characterization and thermal properties of chiral poly(amide-imide)/modified $\mathrm{MgAl}$ layered double hydroxide nanocomposites prepared via solution intercalation. Polym Plast Technol Eng 53:1047-1055

Mohanty S, Nayak SK (2007) Melt blended polystyrene/layered silicate nanocomposites: effect of clay modification on the mechanical, thermal, morphological and viscoelastic behavior. J Thermoplast Compos Mater 20:175-193

Qiu L, Chen W, Qu B (2005) Structural characterization and thermal properties of exfoliated polystyrene/ZnAl layered double hydroxide nanocomposites prepared via solution intercalation. Polym Degrad Stab 87:433-440

Sureshkumar V, Kiruba Daniel SCG, Ruckmani K, Sivakumar M (2016) Fabrication of chitosan-magnetite nanocomposite strip for chromium removal. Appl Nanosci 6:277-285

Tai Q, Chen L, Song L, Hu Y, Yuen RKK (2011) Effects of a phosphorus compound on the morphology, thermal properties, and flammability of polystyrene/MgAl-layered double hydroxide nanocomposites. Polym Compos 32:168-176

Uthirakumar P, Song MK, Nah C, Lee YS (2005a) Preparation and characterization of exfoliated polystyrene/clay nanocomposites using a cationic radical initiator-MMT hybrid. Eur Polym J 41:211-217

Uthirakumar P, Hahn YB, Nahm KS, Lee YS (2005b) Exfoliated high-impact polystyrene/MMT nanocomposites prepared using anchored cationic radical initiator-MMT hybrid. Eur Polym J 41:1582-1588

Wang HW, Chang KC, Yeh JM, Liou SJ (2004) Synthesis and dielectric properties of polystyrene-clay nanocomposite materials. J Appl Polym Sci 91:1368-1373

Wu B, Wang YZ, Wang XL, Yang KK, Jin YD, Zhao H (2002) Kinetics of thermal oxidative degradation of phosphorus-containing flame retardant copolyesters. Polym Degrad Stab 76:401-409

Yeh JM, Liou SJ, Lin CG, Chang YP, Yu YH, Cheng CF (2004) Effective enhancement of anticorrosive properties of polystyrene by polystyrene-clay nanocomposite materials. J Appl Polym Sci 92:1970-1976

Zhang G, Ding P, Zhang M, Qu B (2007) Synergistic effects of layered double hydroxide with hyperfine magnesium hydroxide in halogen-free flame retardant EVA/HFMH/LDH nanocomposites. Polym Degrad Stab 92:1715-1720

Zhao H, Wang YZ, Wang DY, Wu B, Chen DQ, Wang XL, Yang KK (2003) Kinetics of thermal degradation of flame retardant copolyesters containing phosphorus linked pendent groups. Polym Degrad Stab 80:135-140 